\title{
CASEOUS LYMPHADENITIS IN SMALL RUMINANTS: DESCRIPTIVE, EPIDEMIOLOGICAL AND CLINICAL STUDIES
}

Atef F. Oreiby, Salama A. Osman, Yamen, M. Hegazy, Yasser A. Ghanem. and Magdy H. Al-Gaabary.

Animal Medicine Department, Faculty of Veterinary Medicine, Kafrelsheikh University (Egypt)

\begin{abstract}
This study was performed during the period from January 2011 to December 2012 to detect and determine some clinical and epidemiological points associated with Caseous Lymphadenitis in sheep and goat. The prevalence among examined small ruminant populations was $6.74 \%$ and it was significantly higher in sheep (7.54\%) than in goat (3.98\%). There was no significant relation between age and prevalence in both sheep and goat. Concerning sex predisposion, it was found that the disease is not sex-linked one. On the other side, it was found that system of rearing affect significantly the prevalence being highest in fixed flocks.
\end{abstract}

\section{INTRODUCTION}

Caseous Lymphadenitis (CLA) usually affects sheep than goat. It is characterized by severe emaciation, loss of appetite and enlargement of superficial and visceral lymph nodes (Abou-Zaid, 2001). Caseous Lymphadenitis causes significant economic losses to sheep and goat production worldwide for several reasons as reduction in wool, meat, 
milk, reproductive efficiency and condemination of skin and carcasses at abattoirs (Arsenault et al., 2003). A reduction of about 5\% of clean wool production occurs in the first year of CLA infection in sheep (Paton, 2010). The disease has superficial and visceral forms which may coexit in the same animal and may cause sudden death in apparently healthy animal. (Sunil, 2006).

The prevalence of CLA is very low in sheep under 1 year of age but increases dramatically after shearing because of close contact between susceptible fleece- free sheep with those having pulmonary lesions (Windsor, 2011). Environmental hazards such as jutting nails, barbed wire, splintered wood and jagged metal edges which may present in the farm act as a potential risk factor for CLA. Moreover, it was added that shearers contaminated with purulent materials of a CLA lesion facilitate spread of infection to unaffected animals and even leakage of purulent material after aspiration from closed abscesses may considered another risk factor (Williamson, 2001). CLA carrier animals or internally affected animals act as a source of infection to the rest of the flock. It was added that head, neck and oral cavity were the most common sites of entry (Sunil, 2006). Eradication of CLA was difficult due to the rapid spread of the disease once it introduced to a flock (Cetinkaya et al., 2002). The best strategy to control CLA is the vaccination of healthy animals along with identification and culling of infected animals, any control program based on vaccination combined with interferon gamma assay will be the method of choice for control on the long term (Menzies et al., 2004). 


\section{MATERIALS AND METHODS}

\section{Animals:}

Animals of 17 flocks totally 1557 animals (1206 sheep and 351 goats) under different rearing systems (fixed flocks where animals always kept indoors, fixed-mobile flocks where animals graze all over the day and spend its night in a fixed pen and mobile flocks where animals have no fixed pen with continuous changeable grazing areas) at different localities in Gharbia and Kafr El-Sheikh Governorates were used in this study.

Table (1): Breeding systems of the examined animals.

\begin{tabular}{|c||c||c|}
\hline Production system & Number & Number of animals \\
\hline \hline Fixed flocks & 2 & 265 \\
\hline Fixed-mobile flocks & 14 & 1177 \\
\hline Mobile flocks & 1 & 115 \\
\hline
\end{tabular}

Some epidemiological parameters including morbidity rate, rearing system, age and sex susceptibility were estimated according to Martin (1987).

Animals under study were subjected to careful clinical examination according to Rosenberger et al. (1979).

\section{Samples:}

\section{Aspirations:}

Samples were aspirated aseptically with sterile syringes from each closed lesion (abscessiated superficial lymph node) and used for direct microscopy in addition to isolation and identification of the causative agent.

\section{Swabs:}

The opened lesions (ruptured superficial abscesses) were subjected to deep swabbing using sterile cotton swabs. paired swabs were collected from each lesion, the first for direct microscopy, while, the second for isolation and identification of the causative agents.

Samples were subjected to bacteriological examination according to the method described by Bailey and Scott (1990). 


\section{RESULTS}

\subsection{Epidemiological findings:}

Disease frequency, age susceptibility and sex predisposition of caseous lymphadenitis in both sheep and goat in addition to effect of production system on the disease occurrence are listed in Table2, Table 3 , Table 4 and Table 5 respectively.

Table (2): Prevalence of Caseous lymphadenitis in sheep and goa

\begin{tabular}{|c||c||c||c|}
\hline & Totally examined & Affected & \% \\
\hline \hline Sheep & 1206 & 91 & $7.54 \%$ \\
\hline Goat & 351 & 14 & $3.98 \%$ \\
\hline Total & 1557 & 105 & $6.74 \%$ \\
\hline \multicolumn{2}{|c|}{$P<0.037$} \\
\hline
\end{tabular}

Concerning CLA flock prevalence among the clinically examined flocks, it was ranged from $0 \%$ to $16 \%$.

\subsection{Clinical findings of CLA in sheep and goats:}

Clinical signs of Caseous Lymphadenitis varied within and between sheep and goat populations Fig. (1-6) In sheep, abscesses varied in size which may be too small as the size of nuts to reach the size of chicken egg or orange. Contents of such abscesses varied in consistency from milk like material to creamy like or even hard cheese like material and its colour usually was white or bloody white and occasionally greenish in some cases. The wool over the lesion mostly lost except in few numbers of cases.

In some cases in which there was bilateral affected mandibular lymph node showed difficulty in deglutition, chronic recurrent tympany accompanied with chronic ill-thrift and poor condition. 
Caseous Lymphadenitis In Small Ruminants: Descriptive, ...

In other cases there was external lesion accompanied with respiratory disorders which appeared as increased respiratory rate with coughing associated with prolonged emaciation. In rare occasions (one animal) death occurred after prolonged illness appeared as external lesion associated with respiratory disorders.

In goats, signs was milder :lesions as general was smaller in size compared to sheep, content of lesions usually white milky to white creamy, hair over the lesion rarely found lost and there was not any observed respiratory disorders in goat affected by Caseous Lymphadenitis.

Table (3): Effect of age on the prevalence of caseous lymphadenitis

\begin{tabular}{|c|c|c|c|c|c|c|c|c|c|}
\hline \multirow{2}{*}{ Age } & \multicolumn{3}{|c|}{ Sheep } & \multicolumn{3}{|c|}{ Goat } & \multicolumn{3}{|c|}{ Total } \\
\hline & examined & affected & $\%$ & examined & affected & $\%$ & examined & affected & $\%$ \\
\hline Under 1 year & 272 & 22 & $8.08 \%$ & 86 & 4 & $4.65 \%$ & 358 & 26 & $7.26 \%$ \\
\hline $1-2$ years & 477 & 39 & $8.17 \%$ & 174 & 8 & $4.59 \%$ & 651 & 47 & $7.21 \%$ \\
\hline Over 2 years & 457 & 30 & $6.56 \%$ & 91 & 2 & $2.19 \%$ & 548 & 32 & $5.83 \%$ \\
\hline \multicolumn{4}{|c|}{$P>0.60$} & \multicolumn{3}{|c|}{$P>0.59$} & \multicolumn{3}{|c|}{$P>0.57$} \\
\hline
\end{tabular}

Table (4): Effect of sex on the prevalence of caseous lymphadenitis

\begin{tabular}{|c|c|c|c|c|c|c|c|c|c|}
\hline \multirow{2}{*}{ Sex } & \multicolumn{3}{|c|}{ Sheep } & \multicolumn{3}{|c|}{ Goat } & \multicolumn{3}{|c|}{ Total } \\
\hline & examined & affected & $\%$ & examined & affected & $\%$ & examined & affected & $\%$ \\
\hline Male & 211 & 17 & $8.05 \%$ & 78 & 4 & $5.12 \%$ & 289 & 21 & $7.26 \%$ \\
\hline Female & 995 & 74 & $7.43 \%$ & 273 & 10 & $3.66 \%$ & 1268 & 84 & $6.62 \%$ \\
\hline \multicolumn{4}{|c|}{$P>0.75$} & \multicolumn{3}{|c|}{$P>0.55$} & \multicolumn{3}{|c|}{$P>0.69$} \\
\hline
\end{tabular}

Table (5): Effect of breeding system on the prevalence of CLA

\begin{tabular}{|c|c|c|c|c|c|c|c|c|c|}
\hline \multirow[t]{2}{*}{ Age } & \multicolumn{3}{|c|}{ Sheep } & \multicolumn{3}{|c|}{ Goat } & \multicolumn{3}{|c|}{ Total } \\
\hline & examined & affected & $\%$ & examined & affected & $\%$ & examined & affected & $\%$ \\
\hline Fixed flocks & 115 & 30 & $26.08 \%$ & 150 & 10 & $6.66 \%$ & 265 & 40 & $15.09 \%$ \\
\hline $\begin{array}{l}\text { Fixed-mobile } \\
\text { flocks }\end{array}$ & 996 & 59 & $5.92 \%$ & 181 & 4 & $2.20 \%$ & 1177 & 63 & $5.35 \%$ \\
\hline Mobile flocks & 95 & 2 & $2.10 \%$ & 20 & 0 & $0 \%$ & 115 & 2 & $1.73 \%$ \\
\hline
\end{tabular}

Sheep and animals of fixed flocks were significantly associated with high risk of showing the superficial CLA in the study area (P < 0.038),

$\overline{\text { Kafrelsheikh Vet. Med. J. Vol. } 11 \text { No. } 1 \text { (2013) }}$ 
Atef F. Oreiby et., al.

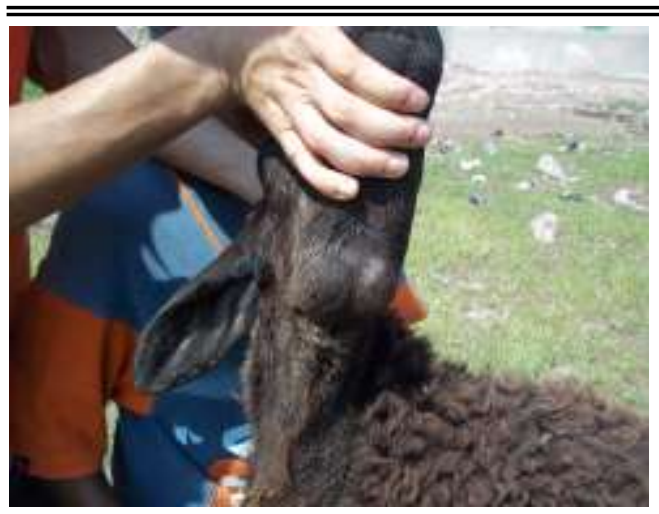

Fig, (1)

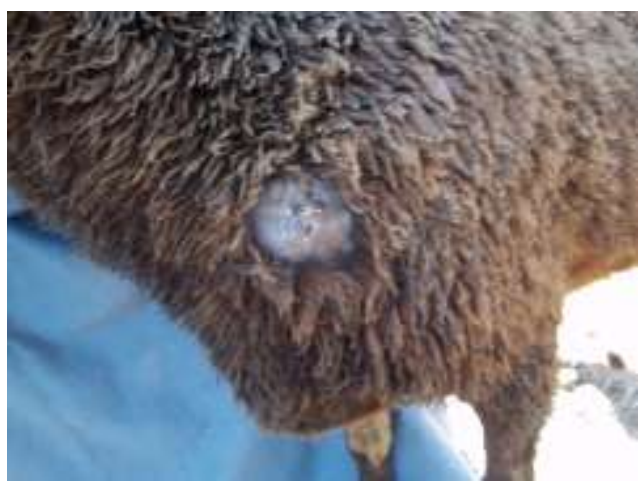

Fig. (3)

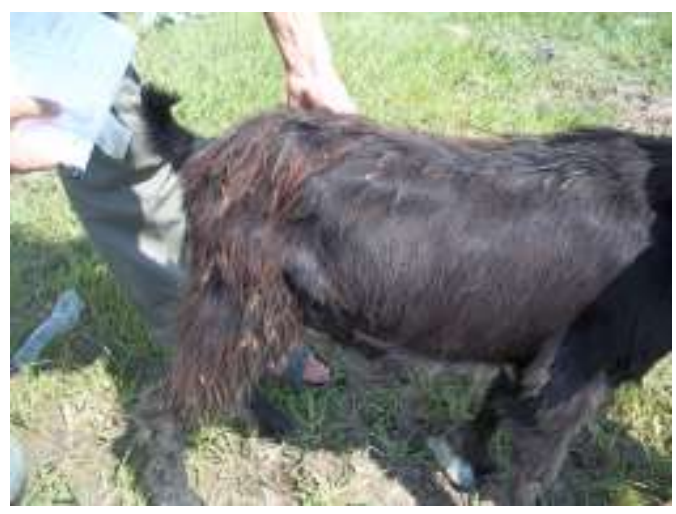

Fig. (5)

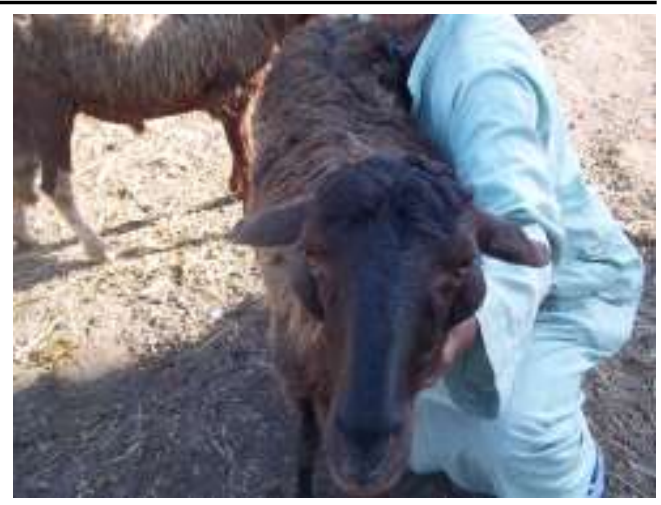

Fig. (2)

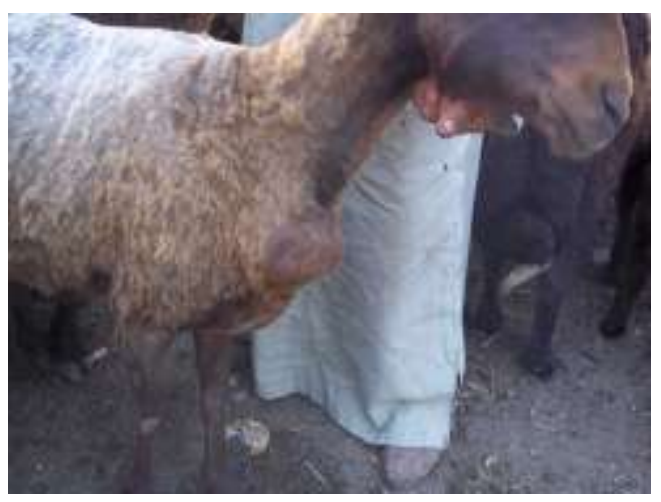

Fig. (4)

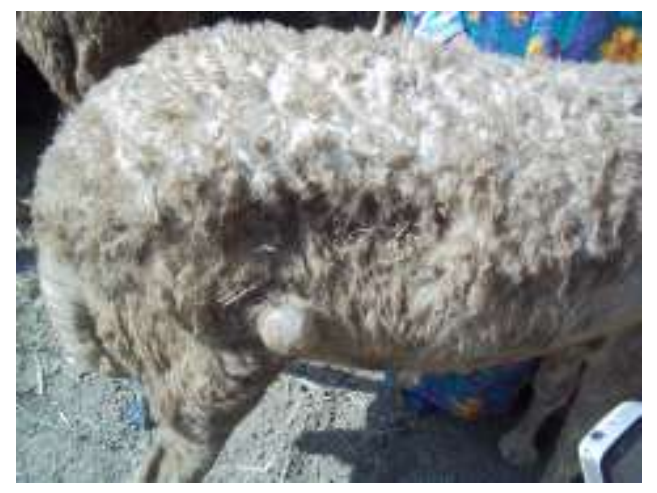

Fig. (6)

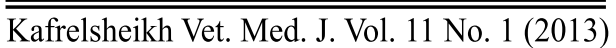


Fig, (1): CLA affected ewe showing bilateral closed mandibular lesions.

Fig. (2): CLA affected ewe showing bilateral closed bilateral parotid lesions.

Fig. (3): CLA affected ewe showing circumscriped alopecia over a superficial cervical lymph node lesion.

Fig. (4): CLA affected ewe showing closed cervical lymph node abscess with an orange size.

Fig. (5): CLA affected doe showing closed right subiliac lymph node lesion.

Fig. (6): CLA affected ewe showing closed right subiliac lymph node abscess.

Regarding the number of lesions in the affected animals, most animals showed only single lesion where 79 out of 105 cases showed one lesion in a percentage of $75.23 \%$ while 21 out of 105 cases showed double or two lesions in a percentage of $20 \%$ and lastly 5 animals out of 105 cases showed multiple lesions (more than 2 lesions) in a percentage of $4.76 \%$.

Concerning the number of lesions in affected sheep, 69 animal out of 91 cases showed signs of Caseous Lymphadenitishad single lesion in a percentage of $75.82 \%$ while, 20 sheep out of 91 cases showed double lesions in a percentage of $21.97 \%$ whereas, 2 out of 91 cases showed multiple lesions in a percentage of $2.19 \%$.

The number of lesions in affected goat, The goat usually had single lesion (10 out of 14) in a percentage of $71.42 \%$ followed by animals which had multiple lesions (3 out of 14) in a percentage of $21.42 \%$ and finally animals with double lesions (1 out of 14) in a percentage of $7.14 \%$.

Concerning the distribution of lesions it was found that most commonly affected lymph nodes were parotid, mandibular, superficial 
cervical, prefemoral, subcutaneous lesions, retropharyngeal and peploteal lymph nodes respectively where it represented $52.94 \%, 19.11 \%, 13.23 \%$, $7.35 \%, 4.41 \%, 2.20 \%$ and $0.73 \%$ from totally found lesions respectively.

In sheep, parotid lymph node lesions was the most commonly affected lymph node where it was found affected in $52.17 \%$ of lesions followed by mandibular lymph node $(22.60 \%)$, superficial cervical

Subcutaneous lesion (4.34\%),retropharyngeal lymph node(2.60\%) and finally the least affected site was peploteal lymph node $(0.86 \%)$.

In goat, the descending arrangement of the most commonly affected lymph nodes was parotid, superficial cervical, prefemoral and subcutaneous lesions which showed a percentage of $57.14 \%, 23.80 \%$, $14.28 \%$ and $4.76 \%$ respectively whereas, there was not any case showed lesions in retropharyngeal, mandibular or peploteal lymph nodes.

Concerning the status of lesion either closed or opened lesion, 109 out of 136 lesions were found closed in a percentage of $80.14 \%$ whereas, 27 out of 136 lesion were found opened in a percentage of $19.85 \%$.

C.pseudotuberculosis was isolated from $6.8 \%$ of clinically affected animals.

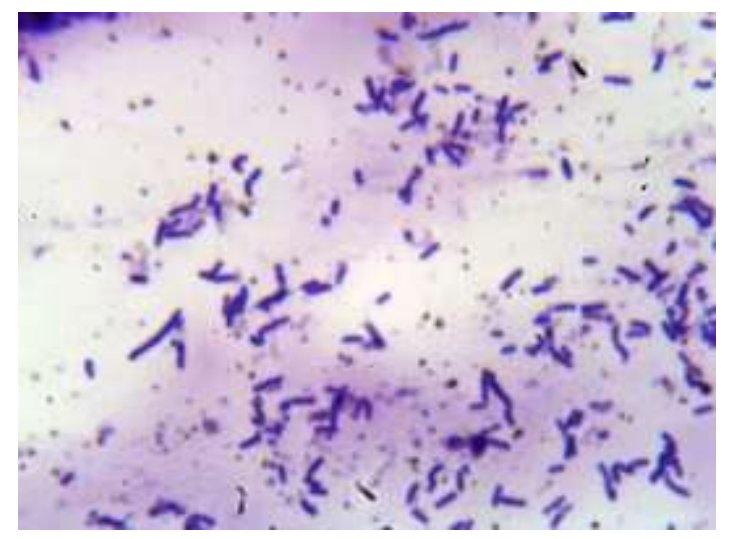

Fig. (7): C.pseudotuberculosis, a bacterial film from colony showing characteristic gram positive rods Chinese letters arrangement. 


\section{DISCUSSION}

Caseous lymphadenitis is a worldwide chronic infectious disease of small ruminants characterized by formation of pyogranulomas mainly in superficial lymph nodes and rarely in visceral lymph nodes and organs Batey et al. (1986) and Paton et al. (1996).

Actual prevalence of CLA is usually under-estimated due to unrecognized cases which discovered only after slaughter Paton et al. (1994) and because of it is a non notifiable disease and owners are not aware of its impacts and do not usually seek for veterinary advice for superficial abscesses Sunil (2006).

The prevalence of Caseous Lymphadenitis among examined small ruminant populations was $6.74 \%$ ( $7.54 \%$ in sheep and $3.98 \%$ in goat). Lower results were reported by Cetinkaya et al. (2002) in Turkey and Komala et al. (2008) in Malaysia who reported prevalence of $2.2 \%$ and $2 \%$ respectively. On the other hand a higher prevalence was recorded by Baird et al. (2004) in the United Kingdom who reported a prevalence of 9.93\%. The variations between different studies refers to different breeding and management systems, different climatic conditions and breed variations in addition to presence or absence of vaccination control programs.

The prevalence of CLA was higher in sheep than goat which may be attributed to species variations where the disease was more severe in sheep than goat and evidence of visceral metastasis was only noted in sheep in addition to a major mangemental factor in sheep which is shearing that allow abrasions to exist repeatedly along the sheep age. Similar view was reported by Musa (1998) who stated that the disease is 
more progressive in sheep than goat. So, generally it is logic to mention that ingestion and inhalation are routes for infection with C.pseudotuberculosis in both sheep and goat but species susceptibility and shearing elevating the prevalence in sheep than goat. This situation necessitates the application of firm hygienic and sanitary preventive measures during shearing.

Caseous lymphadenitis flock prevalence showed marked variation among the studied 17 flocks which ranged from $0 \%$ to $16 \%$. Others reported wider range as Middleton et al. (1991) in Australia who reported flock prevalence to range from $0 \%$ to $56.3 \%$. Variation of CLA flock prevalence highlights the role of managemental procedures participated by shepherds to induce the disease.

Concerning age susceptibility to Caseous Lymphadenitis, the percentage of infection was $7.26 \%, 7.21 \%$ and $5.83 \%$ in animals under 1 year, aged from 1 to 2 years and animals over 2 years respectively. Appearance of the disease in young ages indicate that maternal humeral antibodies just have a partial role to protect against the disease. A supporting view is that of Ellis (1988) who mentioned that each of humeral and cell mediated immunity has a role to protect against CLA.

Caseous lymphadenitis is a non-age linked disease but the occurrence of the disease depends on both internal body environment as pregnancy, lactation, birth, senility and its effects on the immunity and external surrounding environment including mangemental procedures such as shearing, casteration, dehorning, ear tagging or any wound causing objects in addition to stocking density in relation to space area and feeding system. A similar point of view was that of Zaitoun and $\operatorname{Ali}(1999)$. 
Regarding sex predisposition, non-significant variation was found between males $(7.26 \%)$ and females $(6.62 \%)$. In sheep, rams showed a higher infection rate than in ewes where in rams the percentage was $8.05 \%$ and in ewes was $7.43 \%$ while in goat, it was found that bucks showed a higher infection rate than does where the percentage of infection in both bucks and does were $5.12 \%$ and $3.66 \%$ respectively.

Insignificant variation in sex predisposition of CLA in different species indicating that CLA is a non-sex linked disease. The occurrence of the disease in any sex is mainly dependant on immunity which may be altered by senility, gestation, lactation, immunosuppressive disease, nutrition in addition to different mangemental factors to which both sex are subjected to. Similar view was provided by Zaitoun and Ali (1999).

Fixed small ruminant flocks showed the highest infection rate (15.09\%) than fixed-mobile flocks (5.35\%) and mobile flocks $(1.73 \%)$. The highest infection rate in fixed flocks than fixed-mobile and mobile flocks is mainly due to higher environmental contamination with C.pseudotuberculosis in these flocks which has fixed limited space area particularly if there is animals of opened lesions additionally over crowding in fixed flocks facilitate and prolong the contact between CLA infected and CLA free animals. So, environmental contamination with C.pseudotuberculosis represent a risk particularly due to long survival period of C.pseudotuberculosis which may reach 20 weeks (Nanir et al., 1982), 10 days (Jansen, 1983), more than a year (Augustine and Renshaw, 1986), 6 months (Batey, 1986a), 8 months (Brown and Olander,1987). Additionally Paton et al. (1996) reported rapid spread of CLA under the conditions of close contact and presence of covered shed. 
Clinical signs of CLA varied between sheep, goat and from animal to another where closed or opened abscesses were recorded in several superficial sites with different size and characters. Evidence of visceral metastasis was detected in some cases while in others superficial lesions was too small that hardly detected by palpation. CLA in sheep and goat does not cause obvious clinical signs unless the lesions are progressive, very large or numerous to be clinically detected or if their presence affect on the function of a vital organ Paton (2010).

Distribution of superficial Caseous Lymphadenitis lesions revealed that parotid lesions were the most commonly found lesions followed by mandibular, superficial cervical, subiliac, subcutaneous, retropharyngeal and peploteal lesions respectively. A suitable explanation that parotid and mandibular lesions were the most common affected sites indicates that head and neck regions are the most commonly exposed areas for abrasions during grazing in addition to shearing.

Concerning the frequency of lesions, $75.23 \%$ of affected cases showed single superficial abscess, $20 \%$ showed affection in two superficial lymph nodes and $4.76 \%$ showed multiple superficial lesions.. Similarly Al-Gaabary and El-Sheikh (2002) considered animals with single lesion and those with multiple superficial lesions as different two forms of the disease. That is because infection begin as primary lesion in a lymph node and in a lower percentage of cases occur metastasis to other sites, additionally the possibility of infection at two or three different sites may occasionally exist.

Caseous Lymphadenitis abscesses varied in size from the size of nuts to the size of orange or in rare cases may reach the size of melon. 
Consistency of Caseous Lymphadenitis abscess contents varied between milk like fluid to creamy like pus or even hard cheese like materials. Variations in size of CLA lesions is dependant on the stage of the disease and host immune status. This is may explain the variation of the lesion size which was described by other researchers as chicken egg (AbouZaid, 2001), orange (Al-Gaabary and El-Sheikh, 2002) and $15 \mathrm{~cm}$ diameter (Valli and Parry, 1993) while on the other hand others stated that CLA lesions may be very small to detect clinically or even via postmortem examination Pepin et al. (1999).

Concerning the status of lesions, $80.14 \%$ of lesions were in the form of closed abscesses whereas, $19.85 \%$ of lesions were in the form of opened abscesses discharging creamy pus. Caseous lymphadenitis lesions mostly appears as closed abscesses because of the chronic long course nature of the disease and slow ripening of the lesion in addition to being surrounded by thick fibrous connective tissue capsule which accidently may open after ripening or due to traumatic events. Similar findings were reported by Al-Gaabary et al. (2009) and Zaitoun and Bayoumi (1994) who mentioned that some lesions showed spontaneous rupture from central point of abscess.

The detected color of sheep Caseous Lymphadenitis abscess pus was white or yellowish white and occasionally greenish in some cases. The color of Caseous Lymphadenitis lesion pus initially in early stages is greenish due to greenish pigment produced by Corynebacterium pseudotuberculosis and in old lesions, abscesses become nearly sterile so loss of greenish color. Similar view was reported by Jensen (1974) and Valli (1993) who mentioned that old lesions losses its greenish color; the 
same color was detected by Zaitoun and Bayoumi (1994); Mubarak et al. (1999); Williamson (2001) and Al-Gaabary et al. (2009). Another explanation for greenish pus was given by Fontaine and Baird (2008) who referred the greenish color to huge numbers of esinophiles.

Wool over the lesions lost in most examined sheep except in few numbers of cases. Quinin et al. (1994) referred that to the weak dermonecrotic action of the exotoxin produced by Corynebacterium pseudotuberculosis. Another explanation was supplied by Zaitoun and Ali (1999) who referred loss of wool to the pressure atrophy resulted from effect of enlarged lesion on the covering skin.

Difficulty in deglutition, chronic recurrent tympany accompanied with chronic ill-thrift and poor condition were observed in some cases especially in those sheep with bilateral affected mandibular lymph node. Similar signs were reported by Valli (1993); Sayed et al. (1995); Zaitoun and Ali (1999); Williamson (2001); Al-Gaabary and El-Sheikh(2002) and Paton et al. (2005). Presence of such symptoms indicate visceral involvement in addition to pressure created by affected mandibular lymph node on throat region resulting in general health problems in the affected animal resulting from difficult deglutition and rumination.

Milder signs were observed in goat which usually appeared as small sized abscess with whitish milky or creamy pus and hair over the lesion almost present without any evidence of visceral involvement. Brown and Olander (1987); Harker (1990); Lindsay and Lioyd (1991) and Al-Gaabary et al. (2010) confirmed that the disease symptoms were milderin goat while others like Batey (1986a); Brown et al. (1987) and Ivanovic et al. (2009) reported serious or visceral form in goat. These 
results due to the fact that goat is an accidental host for Corynebacterium pseudotuberculosis where a higher adaptability between the organism and sheep due to shearing which ius the major risk factor and which is absent in goat so mild disease in goat with limited chances for visceral involvement.

Corynebacterium pseudotuberculosis was isolated from $6.8 \%$ of CLA clinically affected animals. A higher isolation rates were reported by Alwis et al. (1984), Kuria and Nagattia (1990) and El-Seedy et al. (2005) who reported isolation rates of $85 \%, 79.3 \%$ and $15 \%$ respectively. Low isolation rate is mainly due to nature of lesions which mostly is old lesions containing low numbers of viable organisms, similar opinion was recorded by Baired and Fontaine (2007) who mentioned that failure of isolation is mainly due to CLA old abscesses are mainly sterile. Variation in isolation rates between different studies may be due to different microbiological circumstances under which these studies were performed i.e. used media and lab. Facilities in addition to stage of the disease at which sampling occurred where early lesions provide a higher opportunity for isolation.

\section{REFERENCES}

- Abou-Zaid, A. A. (2001). Corynebacterium pseudotuberculosis in buffaloes, goats and sheep. Veterinary Medical Journal Giza. 49(3): 435-450.

- Al-Gaabary, M. H. and El-Sheikh, W. M. A. (2002). Epidemiological, clinical and preventive studies on caseous lymphadenitis in sheep and goats at Gharbia governorate. $10^{\text {th }} \mathrm{Sci}$. Cong. Fac. Vet. Med., Assiut University, Egypt. 402-417. 
- Al-Gaabary, M. H.; Osman, S. A. ; Ahmed, M. S. and Oreiby, A. F. (2010). Abattoir survey on Caseous Lymphadenitis in sheep and goats in Tanta, Egypt. Small Ruminant Research. 94:117-124.

- Al-Gaabary, M. H.; Osman, S. A. and Oreiby, A. F. (2009). Caseous Lymphadenitis in sheep and goats: clinical, epidemiological and preventive studies. Small Ruminant Research. 87:116-121.

- Alwis, M. C. L.; Wijewardana, T. G. and Bastiansz, H. L. G. (1984). Caseous lymphadenitis in goat farms in Sri-Lanka. Sri-Lanka Veterinary Journal. 32(1/2): 26-29.

- Arsenault, J.; Girard, C.; Dubreuil, P.; Daignault, D.; Galarneau, J. R.; Boisclair, J.; Simard, C. and Belanger, D. (2003). Prevalence of and carcass condemnation from maedi-visna, paratuberculosis and caseous lymphadenitis in culled sheep from Quebec, Canada. Prev. Vet. Med. 59: 67-81.

- Ashfaq, M. K. and Campbell, S. G. (1979). A survey of caseous lymphadenitis and its etiology in goats in the United States. Veterinary Medicine Small Animal Clinician. 74: 1161-1165.

- Augustine, J. L. and Renshaw, H. W. (1986). Survival of Corynebacterium pseudotuberculosis in axenic purulent exudates on common barnyard fomities. Am. J. Vet. Res. 47: 713-715.

- Bailey, A. and Scott, S. (1990). Diagnostic microbiology $8^{\text {th }}$ edition the C.V. Mosby Company. St. Louis.

- Baird, G. J. and Fontaine, M. C. (2007). Corynebacterium pseudotuberculosis and its role in Ovine Caseous Lymphadenitis. J. Comp. Path., 137 : 179-210. 
- Baird, G.; Synge, B. and Dercksen, D. (2004). Survey of caseous lymphadenitis seroprevalence in British terminal sire sheep breeds. Veterinary Record. 154(16): 505-506.

- Batey, R. G. (1986a). Pathogenesis of caseous lymphadenitis in sheep and goat. Australian Veterinary Journal. 63: 269-272.

- Batey, R. G.; Speed, C. M. and Kobes, C. J. (1986). Prevalence and distribution of caseous lymphadenitis in feral goats. Aust. Vet J. 63, 33-36.

- Biberstein, E. L. ; Knight, H. D. and Jang, S. (1971). Two biotypes of Corynebacterium pseudotuberculosis. Vet. Rec. 89:691-692.

- Brown, C. C. and Olander, H. J. (1987). Caseous lymphadenitis of goats and sheep a review. Vet. Bull. 57(1): 1-12.

- Brown, C. C.; Olander, H. J. and Alves, S. F. (1987). Synergistic hemolysis inhibition titers associated with caseous lymphadenitis in a slaughter house survey of goat and sheep in North Eastern Brazil. Can. J. Vet. Res. 51: 46-49.

- Cetinkaya, B.; Karahan, M.; Atil, E.; Kalin, R.; Debaere, T. and Vaneechoutte, M. (2002). Identification of Corynebacterium pseudotuberculosis isolates from sheep and goats by PCR. Veterinary Microbiology. 88(1/2): 75-83.

- Cruickshank, R. ; Duguid, J. P. and Swain, R. H. A. (1975). Medical Microbiology, $12^{\text {th }}$ ed. Volume II. Churchill. Livingstone. Edinburgh, London and New York. 
- Ellis, J. A. (1988). Immunophenotype of pulmonary infilterates in sheep with Caseous Lymphadenitis. Veterinary Pathology. 25: 362-368.

- ElSeedy, F. R.; Selim, S. A.; Radwan, I. A. and Hassan, H. S. (2005). Serological and immunological studies on Corynebacterium Pseudotuberculosis. Assiut Vet. Med. J. 51(106):113-125.

- Fontaine, M. C. and Baird, G. J. (2008). Caseous lymphadenitis. Small Ruminant Research. 76: 42-48.

- Harker, D. B. (1990). Investigation of an outbreak of caseous lymphadenitis in goats in the United Kingdom. Goat. Veterinary Society Journal. 11(2): 52-54.

- Hoyle, L. (1941). A tellurite blood agar medium for rapid diagnosis of diphtheria. Lancet. I.: 175-176.

- Ivanovic, S.; Zutic, M.; Pavlovic, I. and Zujovic, M. (2009). Caseous Lymphadenitis in goats. Biotechnology in Animal Husbandary. 25(5/6): 999-1007.

- Jansen, B. C. (1983). The epidemiology of bacterial infection of the genitalia in rams. Onderstepoort Journal of Veterinary Research. 50: 275-282.

- Jensen, $\boldsymbol{R}$. (1974). Caseous lymphadenitis (C. pseudotuberculosis). Diseases of sheep. Philadelphia, Lea and Febiger, pp. 366-369.

- Komala, T. S.; Ramlan, M.; Yeoh, N. N.; Surayani, A. R. and Sharifah Hamidah, S. M. (2008). A survey of Caseous Lymphadenitis in small ruminant farms from two districts in Perak, Malaysia-Kinta and Hilir Perak. Tropical Biomedicine. 25(3): 196-201. 
- Kuria, J. K. N. and Nagattia, T. A. (1990). Caseous lymphadenitis of sheep and goats in Kenya. Bull. Anim. Hlth Prod. Afr. 38(1): 15-18.

- Lindsay, H. J. and Lioyd, S. (1991). Diagnosis of Caseous Lymphadenitis in goats. The Veterinary Record. 128: 86.

- Martin, W. S. (1987). Veterinary epidemiology. $3^{\text {rd }}$ ed. Iowa State University, Library of Congress.

- Menzies, P. I.; Hwang, T. I. and Prescolt, J. F. (2004). Comparison of an interferon gamma to phospholipase D enzyme linked immunosorbent assay for diagnosis of Corynebacterium pseudotuberculosis infection in experimentally infected goats. Vet. Microbiol. 100: 129-137.

- Middelton, M. J.; Epstein, V. M. and Gregory, G. G. (1991). Caseous lymphadenitis on Flinders Island, prevalence and management surveys. Australian Veterinary Journal. 68(9): 311-312.

- Mubarak, M.; Bastawrows, A. F.; Abdel-Hafeez, M. M. and Ali, M. M. (1999). Caseous lymphadenitis of sheep and goats in Assiut farms and abattoirs. Assiut. Veterinary Medical Journal. 42(83): 89-112.

- Musa, M. T. (1998). Lymphadenitis in sheep and goat in Sudan. Revue d'Elevage et de Medicine Veterinaire des Pays Tropicaux. 51(2): 109-111.

- Nairn, M. E.; Rertson, J. P.; Middleton, H. D. and Mcquade, N. C. (1982). Possibility of control of Caseous Lymphadenitis in goats by vaccination. Proceedings of the Third International Conference on Goat Production and Diseases. 455-457. 
- Paton, M. W. (2010). The epidemiology and control of Caseous Lymphadenitis in Australian sheep flocks. Ph. D. Thesis, School of Veterinary and Biochemical Sciences. Murdoch University.

- Paton, M. W.; Collett, M. G.; Pepin, M. and Bath, G. F. (2005). Corynebacterium pseudotuberculosis infections. In: Infectious diseases of livestock, $3^{\text {rd }}$ Edit., J. A.W. Coetzer and R. C. Tustin, Eds, Oxford University Press Southern Africa, Cape Town, pp. 1917-1930.

- Paton, M. W.; Rose, I. R.; Hart, R. A.; Sutherland, S. S.; Mercy, A. R.; Ellis, T. M. and Dhaliwal, J. A. (1994). New infection with Corynebacterium pseudotuberculosis reduces wool production. Aust. Vet. J. 71: 47-49.

- Paton, M. W.; Rose, I.; Hart, R.; Sutherland, S.; Mercy, A. and Ellis, T. (1996). Postshearing management affects the seroincidence of Corynebacterium pseudotuberculosis infection in sheep flocks. Preventive Veterinary Medicine. 26(3/4): 275-284.

- Pepin, M.; Sanchis, R. and Paton, M. (1999). La linfoadenite caseosa dei gliovinie et dei caprini. Suma. 6: 53-61.

- Quinn, S. G.; Carter, H. E.; Markey, B. K. and Carter, G. R. (1994). Clinical Veterinary Microbiology. 1st Ed. Mosby. Year Book Europe Limited.

- Rosenberger, G.; Dirksen, H. D.; Grunert, E.; Krause, D.; Stober, M. and Mack, R. (1979). Clinical examination of cattle $1^{\text {st }}$ edition, Verlag Paul Parrey, Berlin and Hamburg.

- Sayed, A. M.; Abdel-Fattah, A. M.; Manaa, A. M. and Sayed, A. M. (1995). Caseous lymphadenitis of sheep at Assiut governorate: disease prevalence, lesion distribution and bacteriological studies. 33(65): 88-92. 
- Sunil, V. (2006). Control of caseous lymphadenitis in sheep: Risk factors for disease and validation of an interferon gamma assay. M. V. Sc. Thesis, Faculty of Graduate studies of the University of Guelph.

- Valli, V. E. O. (1993). The hematopoietic system. In: Jubb, K. V. F.; Kennedy, P. C. andPalmer, N. Pathology of Domestic Animals, Vol 3, 4th edn. New York, London: Academic Press.

- Valli, V. E. O. and Parry, B. W. (1993). Caseous lymphadenitis, In: Pathology of Domestic Animals, Vol. 3, $4^{\text {th }}$ Edit. K. V. F. Jubb, P. C. Kennedy and N. Palmer, Eds, Academic Press, San Diego, pp. 238-240.

- Williamson, L. H. (2001). Caseous lymphadenitis in small ruminants. Vet. Clin. North Am. Food Anim. Pract. 17: 359-371.

- Windsor, P. A. (2011). Control of Caseous Lymphadenitis. Vet. Clin. Food Anim. 27: 193-202.

- Zaitoun, A. M. and Ali, H. S. (1999). Clinical and experimental pseudotuberculosis on a multiple ages sheep and goats flock with control trials via treatment and BCG vaccination. Assiut. Vet. Med. J. 42(83): 239-259.

- Zaituon, A. M. and Bayoumi, A. H. (1994). Some epidemiological studies on ovine pseudotuberculosis. Assiut Veterinary Medical Journal. 31(61): 238-250. 